\title{
Measurement of X-ray absorption coefficient of Niobium using the Synchrotron radiation source
}

\author{
G. Manjula ${ }^{1^{*}}$, A.S.NAgeswara Rao ${ }^{2}$ \\ ${ }^{1,2}$ Department of Physics, Kakatiya University, Warangal, 506009, Telangana State, India \\ *Corresponding Author: manjusmahe@gmail.com, Tel.: +919391737293
}

Available online at: www.isroset.org

Received: 02/Dec/2018, Accepted: 18/Dec/2018, Online: 31/Dec/2018

\begin{abstract}
The X-ray absorption coefficient of niobium in the energy range 18.5-19.7 keV around the k-edge is measured using scanning EXAFS synchrotron radiation source. The discrepancies between the measured absorption coefficients and alternative theoretical predictions are discussed.
\end{abstract}

Keywords - Absorption coeffiecient,Synchrotron Radiation, EXAFS

\section{INTRODUCTION}

The motive of the present work is to measure the absorption of Niobium which fulfill the requirements for interaction study in the increasing applications of low energy photons which is also important in basic views of both researches that is atomic physics and in applied physics [1]. The extent of absorption depends on the energy of photon taken by the material. The measurements of absorption values have been reported on the various types of materials such as elements, compounds, tissue equivalent compounds, alloys, heavy metal oxide borate glasses, soils and building materials, etc., [2-11].

\section{RELATED WORK}

X-ray attenuation measurements near the absorption edge using radioactive source were already reported are very limited and in many cases it was the extrapolation method which was used as attenuation values exactly near the edge jump $[12,13]$. To overcome this extrapolation method one need to go for a continuous energy source. Synchrotron radiation (SR) source is one such source which can be tuned near the edge-jump, so that one can also go for accurate measurements near the edge-jump. So, it is worthwhile to undertake absorption measurements to cover some of the existing gaps around the absorption edge and this coefficient is a basic parameter for many studies [14]. A Large number of measurements have been reported over the years to determine attenuation coefficients using synchrotron radiation [15-19]. This encouraged taking up a systematic work in the present study where experimental absorption coefficient is evaluated for Niobium $(\mathrm{Nb})$ element using synchrotron radiation which remains one of the most useful material. The measured values are compared with X-COM
Which was developed by [20] and FFAST [21] theoretical values.

\section{Materials AND Methods}

The element used for the measurement of absorption coefficient data is a pure $\mathrm{Nb}$ metal which was obtained from Good Fellow, England, quoted purity of $99.9 \%$. A method for the determination of the absorption coefficient $(\mu)$ is using synchrotron radiation, which operates in the energy range of 4-25 $\mathrm{keV}$ using $\mathrm{Si}(111)$ doubled crystal monochromator (DCM) have been discussed in [22]. The observed values were compared with theoretical values using $\mathrm{XCOM}$ and FFAST as shown in Figure 1. The X-ray energy absorption fine structure (XAFS) spectra of the sample were recorded in the energy range from 18.5 to $19.7 \mathrm{keV}$, and the absorption coefficient of the sample is determined as a function of energy.

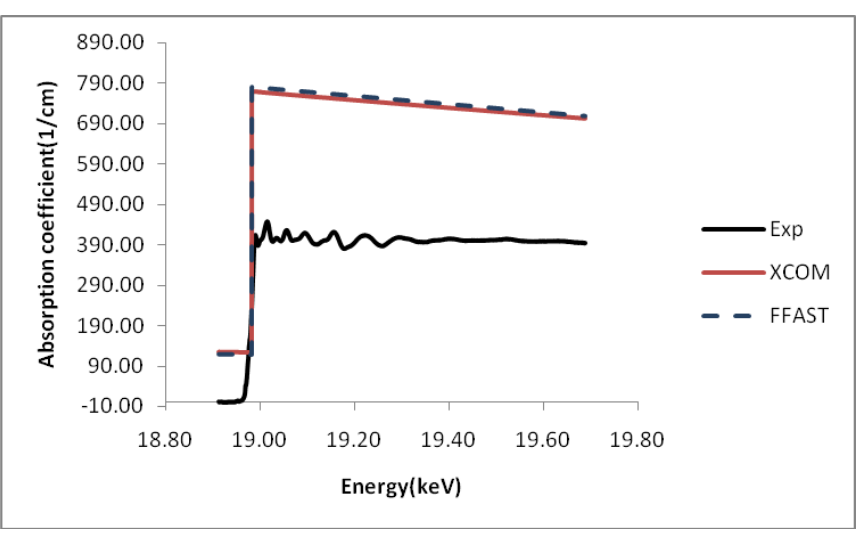

Figure. 1. The XAFS spectra of experimental and theoretical absorption coefficient $(1 / \mathrm{cm})$ for photon energies $(\mathrm{keV})$ of Niobium metal 


\section{RESUlTS AND DISCUSSION}

The results include the observations of the absorption coefficient of $\mathrm{Nb}$ elemental foil using Synchrotron radiation source from energy 18.5 to $19.7 \mathrm{keV}$. The measured values are compared with theoretical values predicted using XCOM method. The measurements were done at an energy step of $0.0003 \mathrm{keV}$. From the graph, in Figure.1, it is observed that near the pre-edge region, i.e., from 18.91 to $18.95 \mathrm{keV}$ the measured values are less than the theoretical values predicted using XCOM and the deviation is $98 \%$. Interesting point is to be noted that there is no oscillatory nature found in the preedge region, which had covered an energy range of 0.045 $\mathrm{keV}$ in the present work. Exactly near the theoretical k-edge jump i.e., $18.99 \mathrm{keV}$, the deviation is $46 \%$. One can see from the Figure. 2 that the experimental k-edge jump energy is $19.009 \mathrm{keV}$. Where the deviation obtained is decreased by $1 \%$ i.e, $45 \%$. The oscillatory nature is seen from 18.98 to $19.28 \mathrm{keV}$, which had covered an energy of $0.304 \mathrm{keV}$ above the observed k-edge jump with absorption coefficient varying from $69-45 \%$. As we are moving away from the observed k-edge jump the oscillatory nature is reduced to smooth line which covered an energy range from 19.28 to $19.68 \mathrm{keV}$. The present work had covered a total energy of less than $1 \mathrm{keV}$ where a fine energy step of $0.0003 \mathrm{keV}$ is used at regular interval to carry the absorption measurements. The oscillatory nature which is seen near the $\mathrm{k}$-edge jump is due to interference phenomenon resulting in positive and negative deviation of $\mu$ values. Peaks in the XAFS spectrum occur due to interference phenomenon of atomic photo electron wave and scattered photo electron wave from neighboring atoms. The measured values are also compared with FFAST theoretical values and the observation does not find much difference when compared with XCOM theoretical readings. The \% discrepancy vs energy graph of present work with XCOM and FFAST is shown in Figure 2.

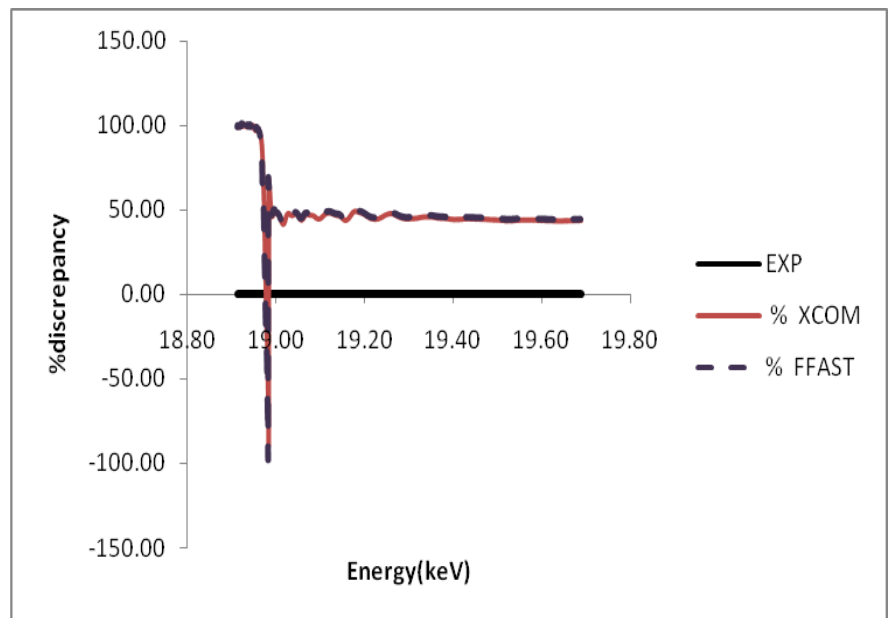

Figure 2. Comparison between theoretical measurements and the present work of niobium

\section{CONCLUSION AND Future Scope}

Using a continuous source (SR) the present work is carried with a very fine energy step of $0.0003 \mathrm{keV}$ exactly near the kedge jump where the measured values are deviating from theoretical values to a large extent. Hence their need of further experimental measurements to overcome the deviations.

\section{ACKNOWLEDGMENT}

One of the authors (GM) is thankful to the RRCAT, Beam Line-09, Indore, India for providing Synchrotron radiation source facility to carry out the study.

\section{REFERENCES}

[1] J.Rehr, \& R.Albers, "Theoritical approaches to x-ray absorption fine structure", Rev.mod.phys,Vol.72, pp.621-654, 2000.

[2] I.Hopkins, John, "Low energy XRay attenuation measurements for elements of low atomic number", J.Appl. Phys.Vol. 30,pp. 185$187,1959$.

[3] K.Parthasaradhi, H.H.Hasen, "Attenuation coefficient measurements for $3.3-165.8 \mathrm{keV}$ photons:Analysis in terms of total photoelectric cross sections", Phys. Rev. A 10, pp.563-568, 1974.

[4] P.P.Kane, G.Basavaraju, K.M.Varier, "Gamma ray attenuation measurements", Nucl. Instrum.Methods Vol.147, pp.507-511, 1977.

[5] L.Gerward, "X-Ray attenuation coefficients for copper in the energy range 5 to 50 ke", Z. Naturforsch37a, pp.451-459, 1982.

[6] L.Gerward, "X-Ray attenuation coefficient of carbon in the energy range 5 to $20 \mathrm{keV}$ ", ActaCrystallographica section. A 39(3), pp.322-325, 1983.

[7] A.S.Nageswara Rao, A.Perumallu, G. Krishna Rao, "Photon cross section measurements in compounds and elements in the energy range 30-660 ke", Physica B+C.124, pp. 96-104,1984.

[8] K.Parthasaradhi, A.Esposito, M.Pelliccioni, "Photon attenuation coefficients in tissue equivalent compounds", Int. J. Appl. Radiat. Isot.Vol. 43, pp.1481-1484, 1992.

[9] A.H.El-Kateb, R.A.M.Rizk, A.M.Abdul-Kader, "Determination of atomic cross-sections and effective atomic numbers for some alloys”, Ann. Nucl. Energy Vol.27, pp.1333-1343, 2000.

[10] M.N.Alam, M.M.H.Miah, M.I.Chowdhury, M.Kamal, S.Ghose, R.Runi, "Attenuation coefficients of soils and some building materials of Bangladesh in the energy range 276-1332 keV", Appl. Radiat.Isot. Vol.54, pp.973-976, 2001.

[11] I.Akkurt, H.Akyildrim, B.Mavi, S.Kilincarslan, C.Basyigit, "Photon attenuation coefficients ofConcrete including barite in different rate", Ann. Nucl. Energy 37(7), pp.910-914, 2010.

[12] D.K.S.Reddy, K.Premachand, V.Radha Krishna Murty, J.Rama Rao, V.Lakshminarayana, "Photoelectric interaction below the Kedge", Phys.Rev. A 13, pp.326-329, 1976.

[13] S.Chandra lingam, K.Suresh Babu, D.V.Krishna Reddy, "Photoelectric cross-section around the Kedge", Physica 122C, pp.348, 1983.

[14] B.R.Kerur, S.R.Thontadarya, B.Hanumaiah, "Photon cross sections around K absorption edges", Indian J. Phys. 67B (6), pp.535-541, 1993.

[15] C.Q.Tran, C.T.Chantler, Z.Barnea, "X-Ray mass attenuation coefficient of silicon:Theory versusExperiment", Phys. Rev. Lett. 90, pp.257401-4, 2003.

[16] Martin.D. de Jonge, Chanh.Q.Tran., T.Chantler Christopher, Dhal .Barnea Zwi, B.Bipin,"Measurement of the x-ray mass attenuation 
coefficientand determination of the imaginary component of the atomic form factor of molybdenum over the $13.5-41.5 \mathrm{keV}$ energy range", Phys.Rev.A 71, pp.032702-16, 2005.

[17] M.T.Islam, N.A.Rae, J.L.Glover, Z.Barnea, M.D.de Jonge, C.Q.Tran, J.Wang, C.T.Chantler, "Measurement of the X-ray mass attenuation coefficients of gold in the $38-50 \mathrm{keV}$ energy range", Phys.Rev. A 81,pp. 022903-9, 2010.

[18] C.T.Chantler, M.T.Islam, N.A.Rae, C.Q.Tran, J.L.Glover, Z.Barnea, "New consistency tests for high accuracy measurements by the X-ray extended-range technique", Acta Cryst. A68, pp.188$195,2012$.

[19] Bunty Rani Roy, A.S.Nageswara Rao, G. Ramana Rao, "New empirical relation for chemical shift and effective charge in the $\mathrm{X}$ ray absorption edge shifts", Spectrochimica Acta Part A: Molecular and Biomolecular Spectroscopy Vol.203 ,pp. 166-176, 2018.

[20] M.J.Berger, J.H.Hubbell, "XCOM: Photon Cross Sections on a Personal Computer", National Bureau of Standards, Gaithersburg, MD, NBSIR 87-3597, 1987.

[21] C.T.Chantler, "Theoritical Form Factor, Attenuation, and Scattering Tabulation for $\mathrm{Z}=1-92$ from $\mathrm{E}=1-10 \mathrm{eV}$ to $=0.4-1.0$ MeV”, J. Phys. Chem. Ref. Data 24, pp.71, 1995.

[22] Bunty RaniRoy, ParasmaniRajput, S.N.Jha, A.S.NageswaraRao, "Measurement of X-ray mass attenuation coefficient of nickel around the K-edge using synchrotron radiation based X-ray absorption study", Radiation Physics and Chemistry 114, pp.3842, 2015.

[23] K.Kouris, N.M.Spyrou, "Usefullness of photon mass attenuation coefficients in elemental analysis", Nucl. Instrum. Methods Vol.153, pp.477-483, 1978.

[24] K.K.Abdullah, K.Karunakaran Nair, N.Ramachandran, K.M.Varier, B.R.S.Babu, Antony Joseph, Rajive Thomas, p.Magudapathy, and K.G.M.Nair , "X-ray attenuation around Kedge of $\mathrm{Zr}, \mathrm{Nb}, \mathrm{Mo}$ and $\mathrm{Pd}$ :A comparative study using protoninduced X-ray emission and 241Am gamma rays", Indian Academy of Sciences, Vol.75, No.3,pp. 459-469,2010. 